\title{
Desenvolvimento de um módulo didático no ensino médio sobre a relação ecológica dos seres humanos com tubarões e piranhas
}

Development of a didactic module in high school on the ecological relation of human with shark and "piranhas"

Jéssica Ricci de Lima ${ }^{1}$, Alessandra Carla Teixeira Ribeiro², Lourdes Aparecida Della Justina ${ }^{3}$, Bárbara Grace Tobaldini de Lima ${ }^{4}$

\begin{abstract}
1 Bolsista CAPES. Universidade Estadual do Oeste do Paraná (UNIOESTE), Brasil. E-mail: jessicaricci1993@hotmail.com 2 Bolsista CAPES. Universidade Estadual do Oeste do Paraná (UNIOESTE), Brasil. E-mail: alessandract.ribeiro@hotmail.com 3 Centro de Ciências Biológicas e da Saúde. Universidade Estadual do Oeste do Paraná (UNIOESTE), Brasil. E-mail: lourdesjustina@gmail.com

4 Centro de Ciências Biológicas. Universidade Federal da Fronteira do Sul (UFFS), Brasil. E-mail: tobaldinibg@gmail.com
\end{abstract}

Recebido em: 22/06/2015 | Aprovado em: 17/04/2017

DOI: 10.12957/interag.2017.16830

\section{Resumo}

Este trabalho é um relato de experiência de uma proposta didático-metodológica que visou à formação de cidadãos críticos em relação à percepção dos seres humanos de peixes considerados perigosos, como é o caso de tubarões e piranhas. A abordagem metodológica adotada foi a de ensino baseada no movimento Ciência, Tecnologia e Sociedade (CTS). Tal abordagem norteia o desenvolvimento de módulos didáticos no Subprojeto Biologia/PIBID/Unioeste. Nesse sentido, o objetivo desse trabalho é apresentar e discutir se houve a desejável reconstrução do conhecimento sobre a relação entre o ser humano e tubarões e/ou piranhas durante o desenvolvimento de um módulo didático estruturado com base na abordagem CTS. Para isto, foram desenvolvidas cinco aulas nas quais se destacamos as seguintes atividades: leitura e discussão de reportagens, realização de um debate e elaboração de redação individual, ambos sobre o conflito entre o ser humano e tubarões e piranhas. Essas atividades foram desenvolvidas com alunos de 15 a 16 anos de uma turma do $2^{\circ}$ ano do ensino médio de um Colégio Público de Cascavel - PR. Ao longo do desenvolvimento das atividades observamos que a abordagem CTS promoveu a participação ativa dos alunos, pois o assunto polêmico despertou mais o interesse dos alunos.

\begin{abstract}
This is the report of a proposal on a didacticmethodological experience to understand the perception by human beings of fish considered dangerous, as is the case of sharks and piranhas. As it is an experience aimed at the formation of critical citizens, the methodological approach adopted was that of teaching based on the Science, Technology and Society (STS) movement. This approach directs the elaboration of didactic modules in the Subproject Biology/PIBID/Unioeste. To this effect, the objective of this report is to present and discuss if there was a desirable reconstruction of knowledge about the relationship between humans and sharks and/or piranhas during the creation of a didactic module structured on the basis of the STS approach. For this, we devised five classes in which we highlighted the following activities: reading and discussion of articles, a debate and the preparation of individual essays, both on the conflict between humans and sharks and piranhas. These activities were conducted with a classroom of 2nd grade high school students, from 15 to 16 years of age, of a state school in Cascavel - PR. Throughout the development of the activities we observed that the STS approach promoted the active participation of students, as the controversial issue sparked more interest from them. In conclusion, we consider that the results obtained with our activities were successful, since it contributed to the
\end{abstract}


Com isso consideramos que os resultados obtidos em nossas atividades foram sucedidos, uma vez que contribuiu para a construção de conhecimentos pelos alunos, no que se refere à resolução de problemas ecológicos.

Palavras-chave: Educação Científica; CTS; Ensino Médio.

Área temática: Educação.

Linha de extensão: Questões ambientais; Metodologia e estratégias de ensino/aprendizagem

\section{Introdução}

Quando se fala de aula de biologia, a primeira coisa que vem a mente de um aluno de ensino médio é um laboratório cheio de animais, experimentos e microscópios. Porém a realidade na maioria das escolas públicas é diferente, pois em muitas não existem laboratórios e quando instalações adequadas ocorrem, poucos professores apresentam o conhecimento e/ou o interesse em utilizá-lo ${ }^{1}$.

Em busca da melhoria do ensino, o Programa Institucional de Bolsa de Iniciação a Docência (PIBID) se torna um aliado na formação de professores, uma vez que possibilita ao aluno da licenciatura um maior contato com o contexto escolar, fazendo com que este vivencie a realidade da rede pública de ensino e obtenha maior conhecimento acerca de técnicas metodológicas e abordagens de ensino².

No contexto PIBID/Biologia da Universidade Estadual do Oeste do Paraná, embasamos as intervenções nas escolas parceiras na abordagem Ciência, Tecnologia e Sociedade (CTS). Segundo Santos e Mortimer ${ }^{3}$, ' 'CTS Significa [..] discutir concepções de cidadania, modelo de sociedade, de desenvolvimento tecnológico, sempre tendo em vista a situação socioeconômica e os aspectos culturais do nosso país".

O objetivo desse trabalho é apresentar e discutir se houve a reconstrução ou mudança no discurso sobre a relação entre o ser humano e tubarões e/ou piranhas durante o desenvolvimento de um módulo didático, no qual esses alunos participaram. A escolha desses animais justifica-se por serem exemplos de peixes, animais em estudo no momento nas turmas estudadas. Tubarões por permear o imaginário dos alunos como 
“criaturas assassinas" e "assustadoras", reforçadas por vezes, na forma como são apresentados em filmes e reportagens. Já a escolha de piranhas por estarem presentes na região geográfica em que a proposta didático-pedagógica foi desenvolvida e com ataques a banhistas recentes em praias do Lago de Itaipu.

\section{A abordagem CTS no Ensino de Biologia}

Trabalhar o conteúdo de uma maneira contextualizada com os alunos chama muito mais a atenção dos mesmos do que aulas meramente expositivas de um mundo não relacionado ao deles, visto que contempla assuntos do seu cotidiano podendo relacionálos com a ciência ${ }^{4}$.

No sentido da conservação, por exemplo, é importante que o aluno saia da sala de aula consciente de que suas ações podem afetar o meio ambiente que o cerca, havendo a destruição do habitat de tubarões e de piranhas como também de outras espécies, incluindo o habitat da espécie humana. Apesar das necessidades humanas, como de se alimentar ou de ter lazer, é possível cumprir essas mesmas com pouco impactos sobre o meio que nos rodeia. Sendo indispensável agregar mais valor aos recursos naturais para que se possa viver com responsabilidade em prol de uma sociedade justa $\mathrm{e}$ ambientalmente saudável ${ }^{5}$.

Esta abordagem possibilita ao aluno uma maior relação com seu ambiente, no qual está inserido diariamente, fazendo com que o mesmo seja o construtor de seus conhecimentos e habilidades. Preparando o estudante para participar crítica e ativamente da sociedade, ajudando a solucionar questões de ciência e tecnologia ${ }^{6}$.

\section{Desenvolvimento da Experiência Didática}

O módulo foi estruturado de forma a contemplar cinco passos, que na prática não são estanques, mas por vezes se sobrepõem no desenvolvimento em sala de aula. Os passos são: (1) introdução de um problema ecológico que envolveu ataques de piranhas e 
de tubarões que vem aumentando a cada ano ${ }^{7}$, sendo importante para mostrar aos alunos o motivo dos ataques de tubarões e como é possível evitá-los ou diminui-los; (2) análise de tecnologias que foram desenvolvidas para diminuir o risco de sofrer acidentes, como roupas para surfistas e nadadores ${ }^{8}$, o Shark Fin Shock, um aparelho que quando adaptado à prancha é capaz de emitir um campo magnético que afasta os tubarões, sem prejudicá-los 9 e o Shark Shield que é um aparelho que emite um campo elétrico ao redor do utilizador. Assim, quando o tubarão se aproxima, é tomado por fortes pulsos eletrônicos, fazendo-o ter espasmos musculares e consequentemente se afastado do mergulhador ou outra pessoa que utilize o dispositivo ${ }^{10}$. Já no caso dos ataques das piranhas, como não há tecnologia para evitar tais ataques, foram apresentadas aos alunos medidas de prevenção, como por exemplo: evitar mergulhar em lagos com placas de avisos de que há piranhas no local; (3) introdução do conhecimento científico relacionando aos peixes cartilaginosos e ósseos com o tema ecológico no âmbito dos ataques; (4) estudo da tecnologia correlatada ao conteúdo científico acerca de peixes considerados perigosos aos seres humanos, como tubarões e piranhas; e, (5) discussão do tema ecológico com relevância social mediante o debate e a elaboração de redações ${ }^{3}$.

Para tanto, foram desenvolvidas as seguintes atividades: leitura e discussão de reportagens sobre ataques de tubarões e piranhas; aula expositiva dialogada a respeito do conteúdo peixes cartilaginosos e ósseos; aula expositiva dialogada da tecnologia relacionada aos peixes, em que levamos imagens de acessórios e roupas que podem diminuir ou impedir esses ataques (como mencionado acima). Ademais, ocorre um debate no qual um grupo defendeu a presença do ser humano na costa oceânica, em rios e lagos e o outro grupo foi contra a presença do ser humano nestes locais. Por último, os alunos escreveram um texto que deveria conter uma possível solução para o conflito entre o ser humano e tubarões e piranhas.

Duas bolsistas de iniciação à docência atuaram como professoras, em uma turma com 27 alunos do $2^{\circ}$ ano com idades entre 15 a 16 do Ensino Médio durante 5 aulas.

Apresentamos o conteúdo aos alunos de diversas maneiras, visando não apenas a apresentação de conhecimento e sim promover uma aprendizagem significativa que 
auxilie na formação de estudantes que tenham e emitam opiniões próprias, com base no conhecimento biológico, sobre a conservação do meio ambiente e a convivência dos seres humanos com outros animais considerados perigosos. $O$ trabalho foi desenvolvido por meio de atividades incluindo leitura de reportagens sobre ataques de tubarões e piranhas, exposição de imagens sobre o conteúdo e vídeos, entre outros, para que pudessem ter uma base para a posterior discussão do tema ataques de tubarões. A forma avaliativa por nós utilizada foi o acompanhamento sistemático da participação de cada aluno em um debate, no qual eles emitiram suas opiniões e na troca de ideias com outros puderam aprimorar seus conhecimentos.

É importante que os alunos compreendam que o que estudam na escola está ligado ao seu cotidiano, podendo assim aplicar esses conceitos em seu dia a dia, decidindo entre abater um tubarão simplesmente porque é perigoso ou deixá-lo viver devido à sua relevância ecológica e respeito à vida. Como professores, nosso papel inclui favorecer o interesse dos alunos a respeito do tema abordado, em particular, e, de uma forma geral, no que tange à ciência, à tecnologia na sociedade contemporânea. Como é exposto por Freitas e Souza ${ }^{4}$, em um artigo que apresenta resultados de uma entrevista com professores que já trabalharam com a abordagem CTS,

Dos professores que afirmam trabalhar em sala de aula com a vida cotidiana do aluno, a principal razão que os leva a utilizar essas situações é fato delas servirem como motivação ao aluno, pois torna a aula mais interessante e chama a atenção pelo conteúdo.

Salientou-se a importância destes animais para o ambiente, explicando que existe uma cadeia alimentar controlada por cada espécie existente e, para que ocorra o seu equilíbrio dinâmico, é essencial que cada espécie tenha certa quantidade de indivíduos levando em conta seu nicho ecológico. Esclarece-se para a turma que os tubarões e piranhas desempenham um papel fundamental para a manutenção da cadeia alimentar, bem como para o meio ambiente devido ao efeito de controle sobre o número das presas. Além do mais, eles são predados em certas ocasiões por orcas como pode ser observado 
no vídeo Orcas Vs Shark: Killer Whales Take Down Tiger Shark ${ }^{11}$. Foi exposto também sobre a relevância que as piranhas exercem sobre a cadeia alimentar, controlando populações de peixes como o dourado, além de se alimentarem de matéria vegetal, ovos e insetos $^{12}$.

\section{Avaliação da Experiência Educacional: Resultados e Discussões}

Para análise dos dados, o recorte volta-se para fragmentos de diálogos construídos no debate e das redações elaboradas pelos sujeitos participantes (A1-A27).

O debate foi realizado na quinta aula, com o intuito de contribuir para a emissão de opiniões dos alunos sobre o assunto discutido, podendo-se observar durante o mesmo que eles haviam entendido o conteúdo e também a percepção de cada um diante do tema estudado. Durante a discussão foram realizadas nove perguntas aos estudantes (Quadro 1).

1 - Você acha que o homem interfere no habitat dos tubarões? No caso, como?

2 - Em quem você colocaria a responsabilidade pelo aumento dos ataques?

3 - Em sua opinião caçar tubarões é correto?

4 - O que você acha a respeito dos esportes aquáticos, como o surf, por exemplo?

5 - Por que tubarões chegam tão perto da costa?

6 - É correto afirmar que o homem é o invasor do habitat dos peixes?

7 - Vocês são a favor da pesca de arrasto de camarões ou de peixes?

8 - Mesmo sabendo que o mergulho, por vezes, pode danificar os recifes de corais e pode prejudicar a fauna marinha, você mergulharia?

9 - Após as opiniões contraditórias, acerca da retirada ou não de animais considerados perigosos de locais usados pelas pessoas, você acha que pode haver de certa forma uma harmonia entre tubarões e seres humanos?

Quadro 1 - Perguntas realizadas no debate aos estudantes.

Fonte: As autoras 
Em relação à segunda pergunta acima mencionada, os alunos responderam que o ser humano é responsável na promoção da segurança e a integridade física do mesmo, pois os peixes carnívoros estão em seu habitat; assim, a invasão ou presença do ser humano nesse local sujeito a ataques por partes de tubarões ou piranhas seria responsabilidade do indivíduo que invadiu. Um aluno afirmou que "O ser humano, porque eles estão no lugar deles, é a gente que vai lá e interfere”.

$\mathrm{Na}$ questão três, um aluno afirmou que "Igual se os cientistas descobrirem uma substância no corpo do tubarão que pode ajudar a acabar com uma doença no mundo, eu acho que pode ser uma causa nobre". Nesta afirmação, o aluno se atenta ao fato de que ao debruçarmos sobre a história da ciência, especialmente em estudos científicos sobre substâncias para tratar doenças, percebe-se que muitas respostas aos questionamentos dessas pesquisas estão em outros seres vivos.

Alguns alunos tiveram opiniões contraditórias em relação à pergunta sete, como pode ser observado na fala de um aluno, na qual afirmou: "Não, porque tira o alimento do tubarão, e depois jogam os restos de alimentos fazendo eles virem próximo a costa e atacando". Já outro aluno afirmou que "Tem restaurantes que tem como prato principal um peixe [...] é a cadeia alimentar como foi falado". Com este argumento o aluno expõe um lado da pesca imprescindível para sobrevivência humana, tanto comercial quanto para subsistência.

Quando realizada a pergunta nove, o aluno declarou que "Eu acho que o ser humano consegue se adaptar a qualquer lugar, por exemplo, nessa escola eu consigo me adaptar se eu for para outra também, então com certeza acho que poderia ter uma harmonia”. Este aluno fez uma argumentação interessante ao associar o conteúdo ao seu cotidiano, ao usar uma analogia de como os seres humanos se adaptam a diferentes situações (habitats) - então pode-se mudar de comportamento em relação aos animais considerados perigosos, como tubarões e piranhas, sem tentar exterminá-los de determinados lugares. 
Como estratégia de ensino, é perceptível que o debate auxilia na formação de cidadãos, pois convida os alunos ao diálogo e estimula seu posicionamento e emissão de ideias a respeito do problema estudado. Outra ideia que se destaca é que cada aluno deve respeitar os argumentos dos outros, porque ao longo de seu desenvolvimento podem surgir novas perguntas que causem conflito entre eles13. Em relação às redações em que pedimos para eles relacionarem o conteúdo trabalhado e colocar possíveis soluções ao problema exposto, observamos que alguns alunos conseguiram compreender o conteúdo, como evidenciam os trechos de dois alunos:

[...] É possivel encontrar um equilíbrio entre essas duas espécies tão diferentes. Explorar sim, mas que haja mais respeito, pois os tubarões também são seres vivos e fazem parte da cadeia alimentar, e sem eles, ela seria abalada e isso afetaria os humanos [...].

[...] Já para os tubarões a perda de habitats e de alimento tem sido muito grande porque além de pescarem muitos peixes tiram o alimento deles. E também na invasão dos corais que mata o peixe acabando com toda uma cadeia alimentar [...].

O primeiro aluno fala que deveria haver mais respeito por parte dos seres humanos com os tubarões e, por meio desta fala e a do outro aluno é possível observar a importância de se explicar a cadeia alimentar para os estudantes.

Em outro trecho, um aluno declara: "[...] Foram desenvolvidas tecnologias para banhistas e surfistas que evitam o tubarão de se aproximar [...]”. Com isto observamos que este participante salientou que a ciência e a tecnologia podem ser úteis para resolver problemas ecológicos como ataques de tubarões, sem prejudicá-los.

\section{Considerações Finais}

Abordar um assunto relacionado ao interesse do aluno o faz prestar mais atenção nas aulas, o que consequentemente torna o aprendizado mais significativo. Além 
do que atualmente vivemos em um mundo em que a tecnologia está muito presente o que acaba envolvendo o aluno.

As relações entre CTS podem ser úteis na aplicação de conteúdos, assuntos polêmicos ou até mesmo pouco conhecidos no domínio científico e tecnológico, visto que alguns conteúdos não são fáceis de integrar ciência, tecnologia e sociedade.

Em nosso módulo acerca de peixes cartilaginosos e peixes ósseos, trouxemos assuntos, imagens e vídeos que aproximassem os alunos do conteúdo, pois esse não está presente no cotidiano dos mesmos, principalmente os peixes cartilaginosos, devido ao fato dos estudantes morarem afastados do litoral brasileiro. Embora o tema não seja local, ele permite refletir a respeito de outros exemplos de "desarmonia" ecológica de diferentes regiões como é o caso das piranhas no lago da Usina Hidrelétrica de Itaipu.

Notou-se que houve momentos de interação do aluno durante as aulas, possibilitando-lhe desenvolver sua capacidade de argumentar e este pode ser aplicado a outros contextos sociais, começando pela família. Entretanto, salientamos que ficou evidente no momento da transcrição e análise dos dados um maior interesse em relação aos tubarões do que as piranhas por parte dos alunos mediante um predomínio desses animais e assuntos relacionados a eles nos diálogos estabelecidos entre alunos e pibidianas, talvez pela ênfase dada aos tubarões nas questões colocadas no Quadro 1.

Consideramos que a forma de avaliar utilizada torna-se mais ampla, pois não utilizamos de instrumentos tradicionais, mas sim, uma discussão entre os alunos, em que eles puderam expor suas opiniões, garantindo um melhor aproveitamento para todos.

\section{Contribuições dos autores}

Alessandra Carla Teixeira Ribeiro e Jéssica Ricci de Lima, acadêmicas do curso de Licenciatura em Ciências Biológicas pela Universidade Estadual do Oeste do Paraná (UNIOESTE), bolsistas do Programa Institucional de Iniciação a Docência (PIBID) no ano de 2014 , foram responsáveis pela execução das atividades com os alunos no ambiente escolar e pela elaboração do relato de experiência. 
Lourdes Aparecida Della Justina, docente da Universidade Estadual do Oeste do Paraná (UNIOESTE), orientadora das bolsistas no Programa Institucional de Iniciação a Docência (PIBID), auxiliou no planejamento e elaboração das atividades, bem como na revisão do relato de experiência.

\section{Referências}

1. SILVA, F. S. S.; MORAIS, L. J. O.; CUNHA, I. P. R. Dificuldades dos professores de biologia em ministrar aulas práticas em escolas públicas e privadas do município de Imperatriz (MA), Revista UNI. Imperatriz, ano 1, n.1, p.135-149, janeiro/julho 2011.

2. PAREDES, G. G. O.; GUIMARÃES, O. M. Compreensões e Significados sobre o PIBID para a Melhoria da Formação de Professores de Biologia, Física e Química. Química Nova na Escola. V. 34, No 4, Pag. 266-277, novembro de 2012.

3. SANTOS, W. L. P; MORTIMER, E. F. Uma análise de pressupostos teóricos da abordagem C-T-S (Ciência - Tecnologia - Sociedade) no contexto da educação brasileira. ENSAIO - Pesquisa em Educação em Ciências. Brasília, V. 02, N. 02, Pag. 01-23, 2012.

4. FREITAS, D.; SOUZA, M.L. CTS no Ensino de Biologia: uma aplicação por meio da abordagem do cotidiano. In: Perspectiva Ciência-Tecnologia-Sociedade na Inovação da Educação em Ciência. Eds. Aveiro, Universidade de Aveiro, Departamento de Didáctica e Tecnologia Educativa, 2004.

5. TORRES, E. M. L. Educação ambiental no ensino fundamental, 2010, 44f., Pós em Educação ambiental. Programa de pós graduação Projeto a voz do Mestre, Universidade Candido Mendes, Rio de Janeiro, 2010.

6. SANTOS, W.L.P. Contextualização no ensino de ciências por meio de temas CTS em uma perspectiva crítica. Ciência \& Ensino, vol. 1, número especial, novembro de 2007.

7. MEDAGLIA, T. Praia do medo. National geographic, São Paulo, p. 33, 46 abril. 2014.

8. BBC BRASIL. Australianos desenvolvem roupa que repele tubarões. 2013. Disponível em: 
http://www.bbc.com/portuguese/noticias/2013/07/130719_invencao_roupa_tubarao_1 lg. Acesso em: 01 de novembro de 2016.

9. NETTLE, S. Shark fin shock: New invention promises surfer safety. In: Swellnet. 2014. Disponível em: http://www.swellnet.com/news/surfpolitik/2014/02/05/shark-fin-shocknew-invention-promises-surfer-safety. Acesso em: 01 de novembro de 2016.

10. SHARK SHIELD. Technology: Get Out There. 2016 Disponível em: https://sharkshield.com/technology/. Acesso em 01 de novembro de 2016.

11. BARCROFT TV. Orcas Vs Shark: Killer Whales Take Down Tiger Shark. Disponível em: https://www.youtube.com/watch?v=uqimOYOQjJ8. Acesso em: 19 de março de 2015.

12. PIORSKI, N. M., et al. Alimentação e ecomorfologia de duas espécies de piranhas (Characiformes: Characidae) do lago de Viana, estado do Maranhão, Brasil. Acta Amazonica, Amazônia, v. 35, n.1, p. 63 - 70, fev. 2005.

13. AltARUGiO, M. H.; DINIZ, M. L.; LOCATELLI, S. W. O Debate como estratégia em aulas de química. Química nova na escola. V. 32, No1, p. 26-30, 2010. 